\title{
Effect of Surface Treatments on Tensile and Flexural Properties of Carbon Fiber Reinforced Friction Material
}

\author{
Naresh Kumar Konada ${ }^{a^{*}, \text { K.N.S.Suman }}{ }^{\mathrm{b}}$ \\ $a^{*}$ Department of Mechanical Engineering, Anits Engineering College, Visakhapatnam, INDIA \\ ${ }^{b}$ Department of Mechanical Engineering, Andhra University College of Engineering, Visakhapatnam, INDIA
}

Received: 19 January 2018; Accepted: 15 March 2018; Published: 08 May 2018

\begin{abstract}
The mechanical properties of a friction material primarily depend on the interfacial adhesion between all the ingredients of a friction material. In this work, a new friction material is developed by combination carbon fiber $(\mathrm{CF})$, polymer matrix and other ingredients. The surface of $\mathrm{CF}$ is chemically inert and hydrophobic in nature and does not possess good bonding property with resin. Therefore, an attempt is made to improve the bonding strength between all the ingredients of a friction material. CF surface is modified by three different surface treatment techniques to increase hydroxyl or carboxyl groups on the surface. First, surface oxidation treatment, Second nitric acid treatment and third grafting multi walled carbon nano tubes functionalized (MWCNT-F) on CF surface. CF content after surface modifications is varied in wt $\%$ and mixed with remaining ingredients. Friction composite sheets are fabricated by using hand layup method. The resulting materials are characterized by SEM, TGA and FTIR analysis. MWCNTs-F on CF surface is observed. Twelve composite sheets with varying content of $\mathrm{CF}$ and surface treatment method is fabricated. Sample specimens are cut from the friction composite sheets to evaluate tensile and flexural properties of friction material. The best surface treatment method and optimum ingredients are selected for the improvement of tensile and flexural properties of friction material.
\end{abstract}

Index Terms: Multi walled carbon nano tubes, Carbon fibers, Chemical grafting, Tensile \& flexural properties.

(C) 2018 Published by MECS Publisher. Selection and/or peer review under responsibility of the Research Association of Modern Education and Computer Science.

\section{Main Text}

Carbon fiber reinforced polymer composites have been gaining their importance in all the fields of 
engineering such as mechanical, civil, aerospace etc. CF is primarily preferred for composite materials due to its excellent properties, such as high specific strength and stiffness, thermal stability, corrosion resistance, high tensile modulus, self lubrication, lower density, good electrical conductivity, lower linear coefficient of expansion and outstanding fatigue characteristics. They are also find applications where high damping and chemical inertness are important [1-4]. Carbon fiber reinforced polymers found to posses superior wear resistance compared to other fibers [5]. The performance and mechanical properties of carbon fiber reinforced composite primarily depends on the interfacial adhesion between fiber and matrix and ingredients selected for the composite. However, CF surface is having poor damage resistance, early fiber matrix de bonding, transverse cracks and de lamination in several applications and it is compensated by over dimensioning of composite parts [6]. The best promising method to improve damage resistance is by growing CNTs on CF. The interfacial properties of the CF and polymer can be improved by modifying the surface of $\mathrm{CF}$ and introducing hydroxyl or carboxyl groups on the surface. Therefore, many efforts have been carried out from the past to improve the surface properties of CF by using different treatment techniques like sizing, plasma, chemical oxidation, $\gamma$-ray irradiation, electrochemical, dip coating, MWCNT grafting on carbon fiber surface by CVD etc [7].

Among the above mentioned various techniques to improve the interfacial adhesion between fiber and matrix, MWCNT grafting on carbon fiber surface under chemical vapour deposition (CVD) achieved good bonding strength between polymer and CF surface. Qiang Song et al [8], Observed that grafting straight carbon nano tubes radially on carbon fiber surface has improved its mechanical properties. The mechanical properties such as compressive strength and inter laminar shear strength are increased by $275 \%$ and $138 \%$ compared to pure C/C Composite. S.P.Sharma et al [9] identified that, coating carbon fibers by using CVD on CF surface improves its tensile strength to $69 \%$ for CF/epoxy/amine polymer matrix composites. Hui Qian et al [10], modified the carbon fiber surface by grafting carbon nano tubes on carbon fibers by CVD technique and observed that, there is $26 \%$ increase in inter laminar shear strength for carbon fiber and poly methyl methacrylate (CF/PMMA) composite. Based on the work carried by many researchers to graft CNTs on CF surface by CVD technique improved its interfacial shear strength, mechanical and tribological properties to a greater extent. But, grafting CNTs on CF surface by using CVD is a costlier process and involves care in controlling of the operating temperatures. Therefore, an alternative method is followed in this work by modifying the CF surface by three chemical treatment methods and, the best surface treatment method is selected with optimum ingredients for improving the tensile and flexural properties of a friction material. [11$16]$.

\section{Materials and Methods}

The friction materials selection depends on ability of the material to with stand the given pressure and satisfying all the important characteristics of a friction material. The wear rate of friction material depends on the type of friction material used, pressure applied on the pads, friction material temperature, friction material contact area, friction material finish, Heat removal rate etc. Therefore, selection of ingredients for the friction material was carried out based on the characteristics of a friction material.

The main characteristics of friction materials should possess are [17]:

(i) Maintain a sufficiently high coefficient of friction with the brake disc.

(ii) Not to decompose or break down in such a way that the friction coefficient with the brake disc is compromised, at high temperatures.

(iii) Exhibit stable and consistent coefficient of friction with the brake disc.

(iv) Wear resistant.

(v) Able to dissipate heat to the surroundings.

(vi) Having sufficient fade resistance.

(vii) Induce less squealing action and should be operated over different atmospheric conditions. 


\subsection{Carbon Fiber}

Commercially available, polyacrylonitrile (PAN) based chopped carbon fibers were used for this study. Chopped carbon fibers having a carbon content of $95 \%$ is used in the present work. The collected chopped carbon fibers before thermal oxidation treatment are shown in fig 1. The properties of chopped carbon fibers given by the supplier are indicated in table1.

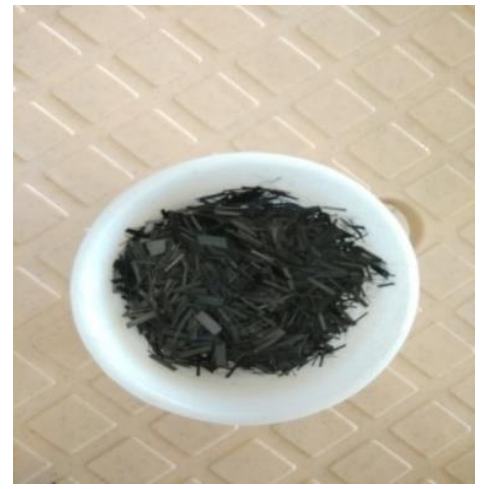

Fig.1. Chopped Carbon Fiber

Table 1. Properties of Carbon Fiber

\begin{tabular}{cccccccc}
\hline Material & Diameter & Length & $\begin{array}{c}\text { Tensile } \\
\text { strength } \\
(\mu \mathrm{m})\end{array}$ & $\begin{array}{c}\text { Tensile } \\
\text { modulus } \\
(\mathrm{mm})\end{array}$ & $\begin{array}{c}\text { Sizing } \\
(\mathrm{MPa})\end{array}$ & $\begin{array}{c}\text { Resistivity } \\
\Omega / \mathrm{cm}\end{array}$ & $\begin{array}{c}\text { Carbon } \\
\text { content }\end{array}$ \\
\hline & & & & & & & \\
Carbon fiber & 6.9 & 6 & 4810 & 225 & $1-1.2 \%$ & $1.54 \times 10^{-3}$ & $95 \%$ \\
\hline
\end{tabular}

\subsection{Multi Walled Carbon Nano tubes (MWCNT)}

Multi walled carbon nano tubes (MWCNT) used in the present study is produced by using chemical vapour deposition method (CVD). This is shown in fig 2. MWCNTs are used widely, as filler materials in polymer matrix composites applications like structural, industrial, and aerospace sectors. The damping characteristics and toughness behaviour of the composites reinforced with MWCNTs are observed to be greatly improved. Hence, in this work MWCNTs are selected to use in organic friction composite .The properties of MWCNT supplied by the supplier for the given study are given in table 2. Chemicals such as $\mathrm{NaOH}, \mathrm{HNO}_{3}, \mathrm{H}_{2} \mathrm{SO}_{4}$, acetone solutions used in the current study is purchased from chemical laboratories, Visakhapatnam, India. 


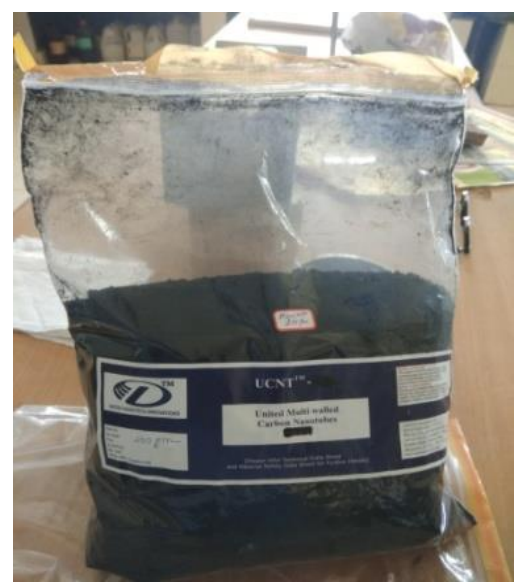

Fig.2. MWCNT Powder

Table 2. Properties of Multi Walled Carbon Nano tubes

\begin{tabular}{|c|c|c|c|c|c|c|c|}
\hline Material & Diameter & Length & $\begin{array}{c}\text { Metal } \\
\text { particles }\end{array}$ & $\begin{array}{c}\text { Amorphous } \\
\text { Carbon }\end{array}$ & $\begin{array}{c}\text { Specific } \\
\text { surface } \\
\operatorname{area}\left(\mathrm{m}^{2} / \mathrm{g}\right)\end{array}$ & $\begin{array}{c}\text { Bulk } \\
\text { density }\end{array}$ & $\begin{array}{l}\text { Nano } \\
\text { tubes } \\
\text { purity }\end{array}$ \\
\hline & $(\mathrm{nm})$ & (microns) & & & & $\mathrm{g} / \mathrm{cm}^{3}$ & \\
\hline MWCNT & 10 to 30 & 10 & $<4 \%$ & $<1 \%$ & 330 & $\begin{array}{c}0.04- \\
0.06\end{array}$ & $>95 \%$ \\
\hline
\end{tabular}

\subsection{Carbon fiber Surface Treatment Methods}

\subsection{1 $\mathrm{HNO}_{3}$ treatment}

Carbon fibers (CF) of quantity 180 gms were modified by dipping in a solution of $40 \% \mathrm{HNO}_{3}$ i.e. $(200 \mathrm{ml}$ of $\mathrm{HNO}_{3} \& 300 \mathrm{ml}$ of distilled water) for $48 \mathrm{hrs}$ at room temperature. The fibers were allowed to immerse completely in the nitric acid solution and distilled water. Few gases will generate during mixing process of $\left(\mathrm{CF}+\mathrm{HNO}_{3}+\right.$ distilled water). The complete mixing operation has to be performed slowly. Initially, $50 \mathrm{ml}$ of $\left(\mathrm{HNO}_{3}+\right.$ distilled water) is poured on the surface of CF. Allow the sample to rest for $5 \mathrm{~min}$. This operation is continued for four times with interval time gap period of $5 \mathrm{~min}$ for allowing the gases to escape to the atmosphere. The collected carbon fibers were allowed to drain out the immersed liquid. Then, CF surface was diluted with distilled water of 3lit qty. First CF surface was diluted with 1 lit qty of distilled water and wait for 30 mins to allow the distilled water to completely mix with the CF surface. Then, the liquid is drained out. This process is repeated for 3 times to remove $\mathrm{HNO}_{3}$ liquid gases adsorbed on $\mathrm{CF}$ surface. Now, CF surface is immersed in $\mathrm{NaOH}$ solution of $10 \%$ qty $\left(300 \mathrm{ml}\right.$ of distilled $\mathrm{H}_{2} \mathrm{O}+30$ gms of $\left.\mathrm{NaOH}\right)$ and allow the sample to completely soak for 30 mins. Finally, CF surface is diluted with distilled water of 2 lit qty to remove left over acid gases adsorbed on its surface. This process of dilution, initially with $\mathrm{HNO}_{3}$ and finally with $\mathrm{NaOH}$ makes the surface completely free from adsorbed gases on CF surface. The collected carbon fibers after complete 
dilution process were allowed dry in an oven at a temperature of $150^{\circ} \mathrm{C}$ for $2 \mathrm{hrs}$ followed by drying in atmosphere for $1 \mathrm{hr}$. The sequence of operations carried in $\mathrm{HNO}_{3}$ treatment is shown in fig 3 .
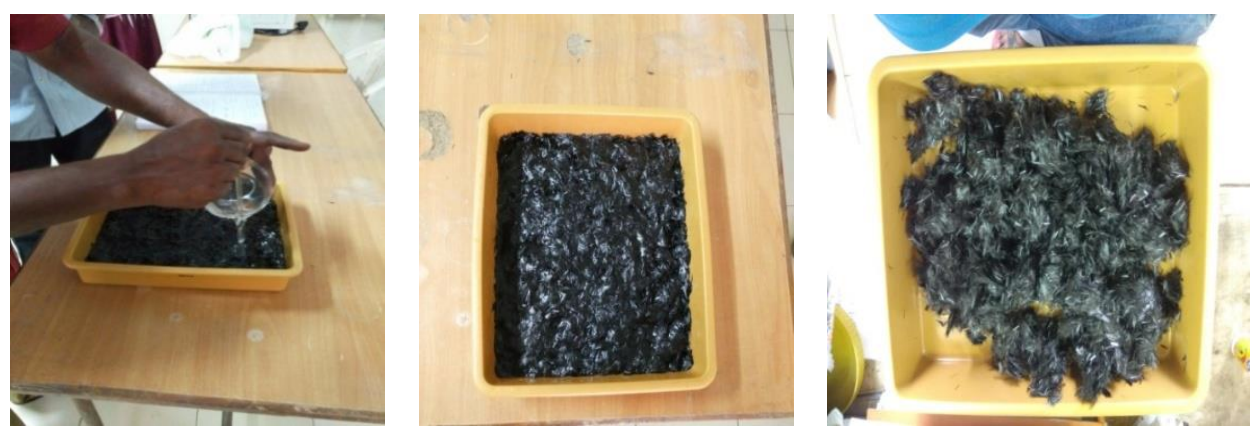

Fig.3. Sequence of operations carried in $\mathrm{HNO}_{3}$ treatment on $\mathrm{CF}$

\subsubsection{Surface Oxidation Treatment On Carbon Fibers}

Chopped carbon fibers collected in the crucible are subjected to surface oxidation treatment in an oven at 600

${ }^{0} \mathrm{C}$ for $1 \mathrm{hr}$. First, temperature is increased from $20^{\circ} \mathrm{C}$ to $600^{\circ} \mathrm{C}$ for $30 \mathrm{~min}$ under nitrogen gas and in a second step temperature is kept at $600^{\circ} \mathrm{C}$ for remaining duration time of $30 \mathrm{~min}$ under air. The $\mathrm{CF}$ surface is modified by thermal oxidation treatment in this step to improve the bonding behaviour of $\mathrm{CF}$ with remaining ingredients.

\subsubsection{MWCNT Surface Oxidation Treatment}

Multi walled carbon nano tubes (MWCNTs) are treated to attach carboxylic acid groups on its surface to form functionalized MWCNTs (MWCNT-F). In this step, $2 \mathrm{gms}$ of MWCNT are added to $100 \mathrm{ml}$ of concentric sulphuric acid and $35 \mathrm{ml}$ of nitric acid of (Purity of $98.08 \% \mathrm{H}_{2} \mathrm{SO}_{4}$ and $\left.70 \% \mathrm{HNO}_{3}\right)(3: 1$ by volume ratio) . The mixture is sonicated in a bath for $3 \mathrm{hrs}$ at a temperature of $70^{\circ} \mathrm{C}$. Now, the reaction mixture is diluted with $200 \mathrm{ml}$ of deionised water followed by vaccum filtration process using a filter paper of $2 \mu \mathrm{m}$ porosity. This dilution is repeated for three times to remove the metal particles adsorbed on MWCNTs. The sample is allowed to dry in an oven at $100^{\circ} \mathrm{C}$. After drying operation, the collected MWCNT powder particles are immersed in 40 $\mathrm{ml}$ of acetone solution and placed on a ultra sound bath sonicator to allow the acetone solution to completely mix with MWCNTs. During sonication process, acetone gases will escape to the atmosphere because of having low boiling point of acetone i.e $30^{\circ} \mathrm{C}$. Now the collected sample powder is dried in oven at $100^{\circ} \mathrm{C}$ for $4 \mathrm{hrs}$ followed by drying in atmosphere to form MWCNT-F powder. This process will completely removes metal particles present in MWCNT powder to use MWCNT-F more effectively in polymer matrix composites. This process of using MWCNT-F on CF polymer matrix composites can increase the damping characteristics of the friction composite and reduce the squeal genetation at the contact region between brake disc and pad. Fig 4. gives sequential operations performed in functionalisation of MWCNTs powder. 

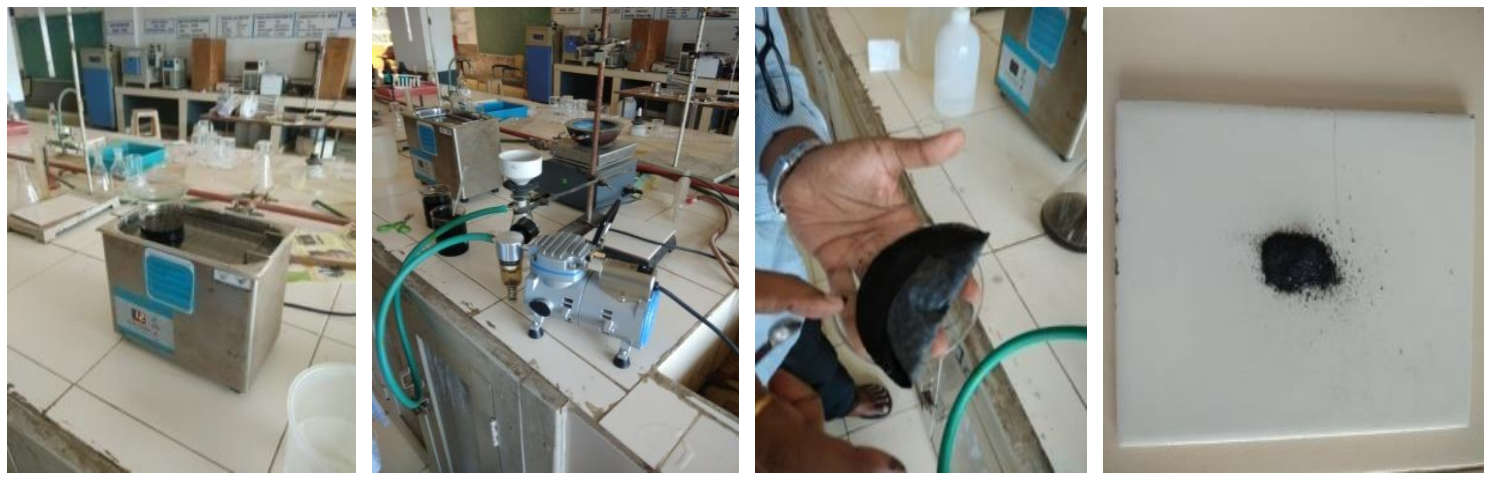

Fig.4. Sequential Operations Performed in MWCNT Surface Oxidation to form MWCNT-F

\subsubsection{Grafting MWCNT-F on Carbon Fibers}

Multi walled carbon nano tubes functionalized (MWCNT-F) of qty 1.5 gms obtained after vaccum filtration and drying operation is dispersed in a $20 \mathrm{ml}$ of acetone solution. Ultra sound bath sonication method is used for complet dispersion of MWCNT-F and acetone solution. The operating temperature of ultra sound bath system is kept at $70^{\circ} \mathrm{C}$ for $1 \mathrm{hr}$. Now, chopped carbon fibers are placed on a glass substrate and suspension containing MWCNT-F is deposited drop by drop using a droppler technique on the complete surface of carbon fiber.The deposition operation is repeated several times with evaporation of the sovent between each deposition. Heat treament process is carried on the resulting CFs grafted with MWCNT-F at $100^{\circ} \mathrm{C}$ for $2 \mathrm{hrs}$. Fig 5. gives sequential operations performed in grafting MWCNT-F on carbon fiber surface.
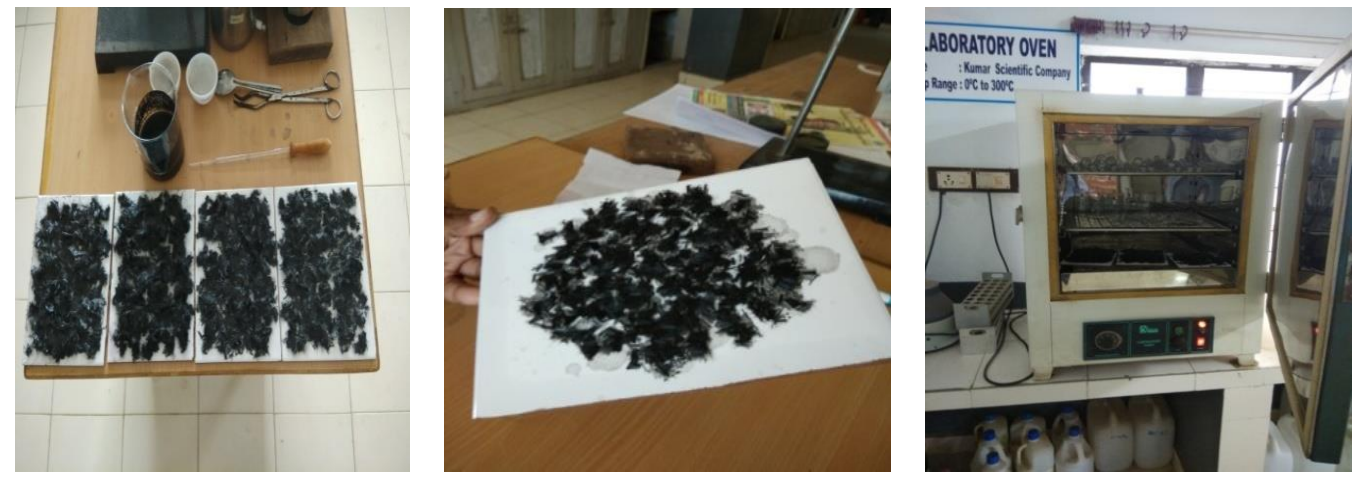

Fig.5. Grafting MWCNT-F on CF Surface

\section{Preparation of Composite Sheets}

Preparation of friction composite sheets are carried by using hand lay up process, owing to its cost effectiveness and significant control over operating parameters compared to remaining methods. CF after surface treatment is mixed with other ingredients using a foculator for $30 \mathrm{~min}$ for each sample sheet. Initial step of fabrication involves preparing a die with dimensions of $42 \mathrm{~cm} \times 22 \mathrm{~cm} \times 1.2 \mathrm{~cm}$ made of mild steel material. The die is finished to remove the unwanted material of thickness $2 \mathrm{~cm}$ on all the sides by gas welding operation. Initially resin is taken in a foculator and all the ingredients are added slowly one after the other with an interval time period gap of 10 min. Total mixing operation for all the ingredients was carried for 30 min for each 
sample sheet. Twelve composite sheets with variation of surface treatment performed on CF are fabricated. Samples are cut as per ASTM standards to evaluate tensile and flexural characteristics of each specimen. The details of ingredients selected for fabrication of composite sheets are given in table 3 and the sequence of operations involved in fabrication of friction composite sheets is given in fig 6 .
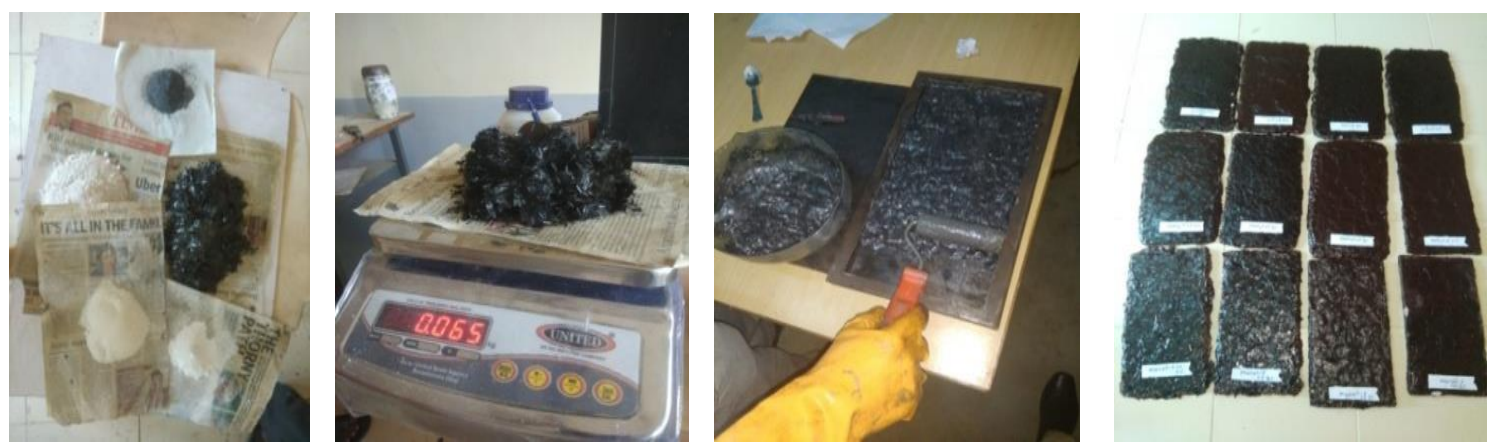

Fig.6. Sequence of Operations Performed In Fabrication of Composite Sheets

Table 3. Material Selection

\begin{tabular}{|c|c|c|c|c|}
\hline Material & $\begin{array}{l}\text { Sample } \\
\text { S2 }\end{array}$ & Sample S3 & Sample S4 & $\begin{array}{l}\text { Sample } \\
\text { S5 }\end{array}$ \\
\hline $\begin{array}{c}\text { CF After surface treatment [Oxidation, } \\
\mathrm{HNO}_{3}, \mathrm{MWCNT}-\mathrm{F} \text { grafted] }\end{array}$ & $2 \%$ & $3 \%$ & $4 \%$ & $5 \%$ \\
\hline Phenolic Resin & $70 \%$ & $70 \%$ & $70 \%$ & $70 \%$ \\
\hline Zirconium Silicate ( $\mathrm{ZrSiO} 4)$ & $20.50 \%$ & $20 \%$ & $19 \%$ & $20 \%$ \\
\hline Graphite & $1.50 \%$ & $1 \%$ & $1 \%$ & $0.50 \%$ \\
\hline Barium sulphate (BaSO4) & $2.50 \%$ & $3 \%$ & $2.50 \%$ & $1.50 \%$ \\
\hline Rubber Powder & $3.50 \%$ & $3 \%$ & $3.50 \%$ & $3 \%$ \\
\hline Total & $100 \%$ & $100 \%$ & $100 \%$ & $100 \%$ \\
\hline
\end{tabular}

\section{Thermo Gravimetric Analysis (TGA)}

TGA is a method of thermal analysis in which the mass of a sample is measured over time as the temperature changes. This measurement provides information about physical phenomena, such as phase transitions, absorption and desorption, chemical phenomena including chemisorptions, thermal decomposition and solid 
gas reactions (eg. oxidation or reduction). A thermo gravimetric analyzer continuously measures mass while the temperature of a sample is changed over time. Mass, temperature, and time in thermo gravimetric analysis are considered as base measurements while many additional measures may be derived from these three base measurements. The present analysis is performed on powder sample collected from the friction composite specimen S5 with (MWCNT-F grafted on CF wt5\%). The temperature is increased slowly from $0^{\circ} \mathrm{C}$ to $1000^{\circ} \mathrm{C}$ for an ending time period of $112.6 \mathrm{~min}$. The oxidative mass loss is continuously observed with increase in temperature. The weight loss for the sample S5 is observed to be very less compared to other formulations of the material (i.e $2.11 \mathrm{mg}$ ). The optimum selection of ingredients makes the sample S5 (MWCNT-F grafted on $\mathrm{CF} w \mathrm{t} \%$ ) to sustain high temperatures easily and there is no considerable mass loss is observed after TGA analysis. Fig 7 gives TGA performed on sample S5 (MWCNT-F grafted on CF wt5\%) of sample powder with increase in temperature.

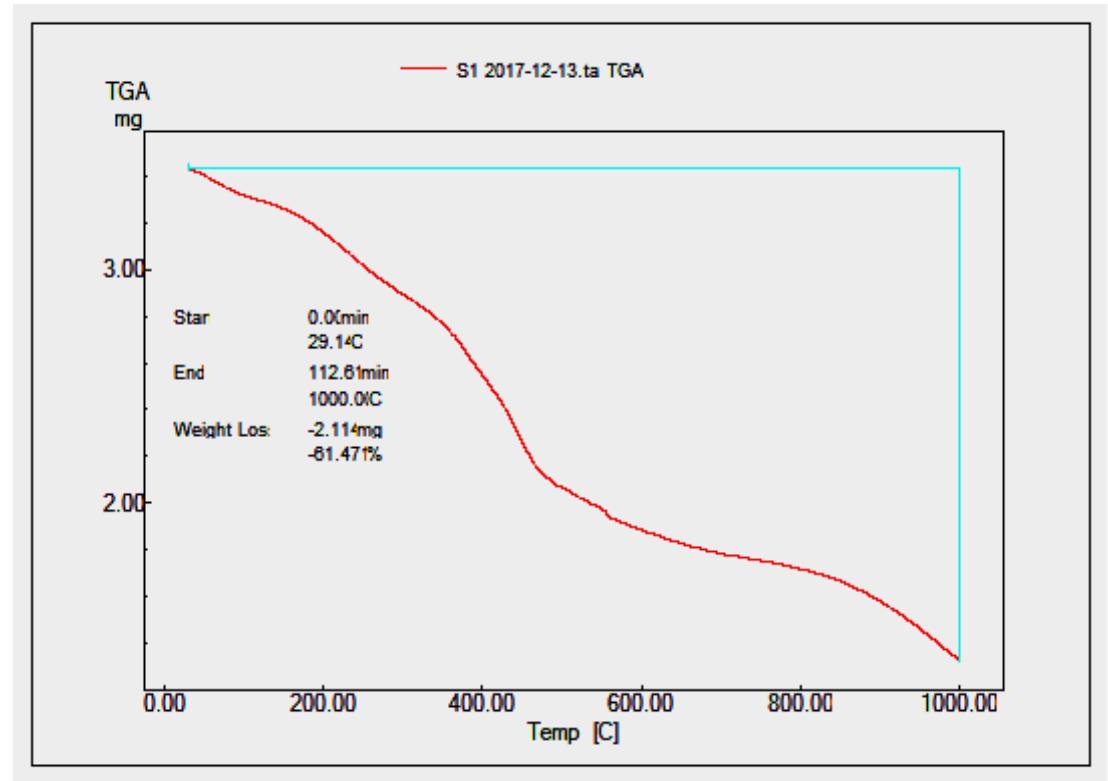

Fig.7. TGA Analysis on Powder Sample of S5 (MWCNT-F grafted on CF)

\section{Fourier Transform Infrared Spectroscopy Analysis (FTIR)}

FTIR is a technique used to obtain an infrared spectrum of absorption or emission of a solid, liquid or gas. An FTIR spectrometer simultaneously collects high spectral resolution data over a wide spectral range. This converts the raw data in to the actual spectrum. The main aim of FTIR is to observe how well the sample absorbs light at each wavelength. FTIR spectroscopy of make shimadzu is used for this purpose. All the samples are subjected to infrared monochromatic light and intensity of peaks at each wavelength varying from $4000 \mathrm{~cm}^{-}$to $400 \mathrm{~cm}^{-}$is observed. It was observed that, the intensity of peak begins at 44.416 and stops at a value of 40.824 for the sample S5 (CF wt5\%) for CF grafted with MWCNT-F. The intensity of peak value is having fewer fluctuations with increase of wavelength and the variation between all the values of intensity of peaks is very less. The inter laminar cohesive forces between all the ingredients are greatly improved after surface treatment method by grafting MWCNT-F on CF surface compared to remaining methods. The sample specimen S5 (CF wt5\% and CF grafted by MWCNT-F) possess good bonding strength with resin compared to other formulations of the material. The absorption spectra and intensity of peaks with respect to wavelength for sample S5 is given in fig 8 . 


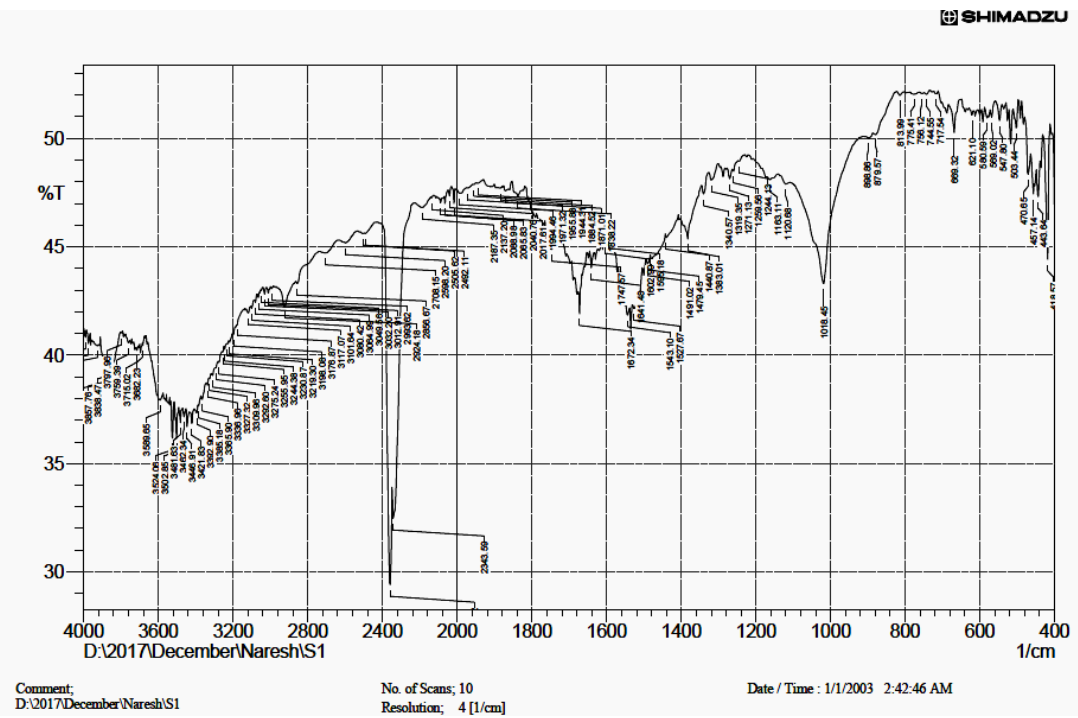

Fig.8. FTIR analysis on Specimen S5 (MWCNT-F grafted on CF)

\section{Scanning Electron Microscopy Results}

The SEM images given in Fig 9(a), Fig 9(b) \& Fig 9 (c) demonstrate the three different surface treatments performed on CF. The surface visualization can be observed from each fabricated composite specimen in the SEM images. Fig 9(a) represents the CF surface subjected to oxidation treatment. The chemical inertness of the CF surface is not greatly improved by this treatment. This can be visualised in Fig 9(a) with shiny colour on its surface.

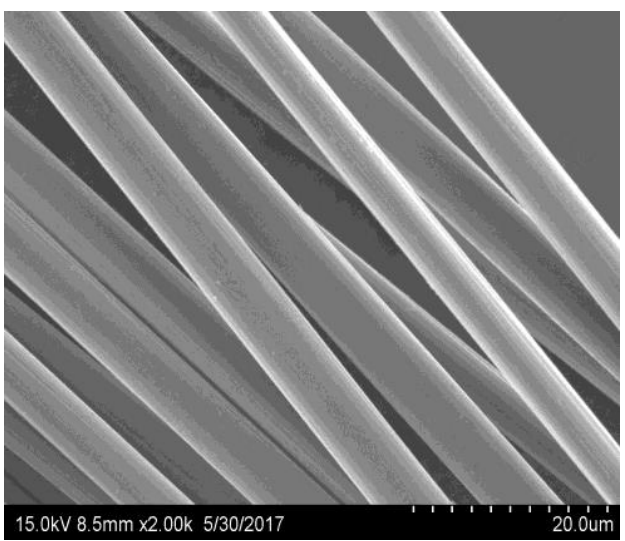

Fig.9(a). Surface Oxidation Treated CF

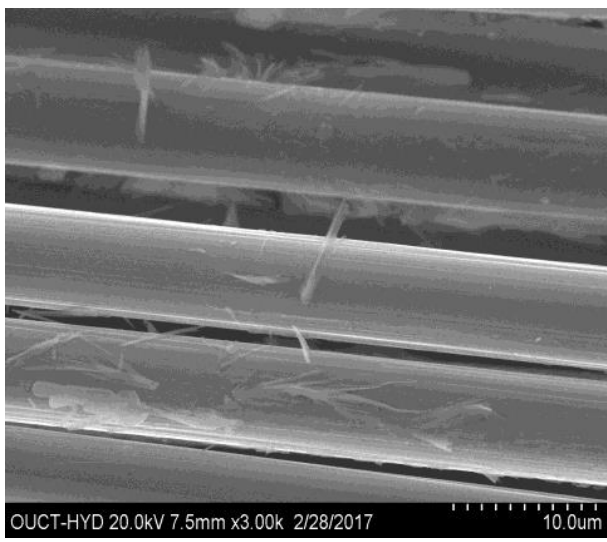

Fig.9(b). HNO3 Treated CF 


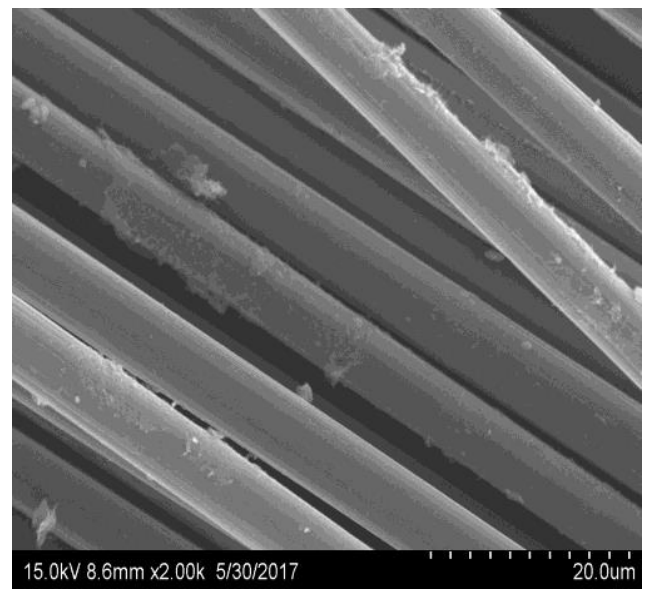

Fig.9(c). MWCNT-F Grafted on CF

Fig 9(b), shows $\mathrm{HNO}_{3}$ treated $\mathrm{CF}$ with improved chemical inertness of the fiber to greater extent by incorporation of hydroxyl groups on the surface of $\mathrm{CF}$. The fiber surface after $\mathrm{HNO}_{3}$ treatment becomes soft and smooth to increase bonding strength, when mixed with all ingredients and resin. Further improvement of chemical inertness of the surface is increased by introducing more carboxyl groups on the surface by grafting MWCNT-F on CF surface shown in Fig 9(c). The surface structure of the carbon fiber becomes rough and there may be greater chance for increase of cohesive forces between all the ingredients. This type of grafting MWCNT-F on CF surface improves bonding strength of all ingredients with resin and possesses good mechanical and tribological properties without compromising its strength.

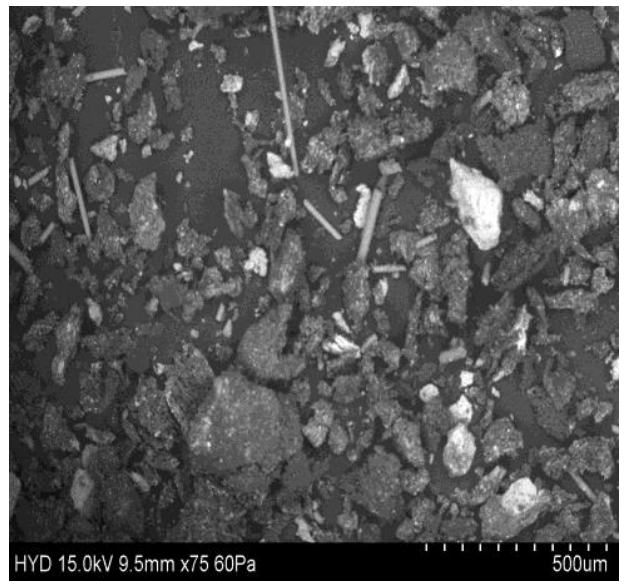

Fig.9(d). Surface Oxidation Treated Composite Sheet

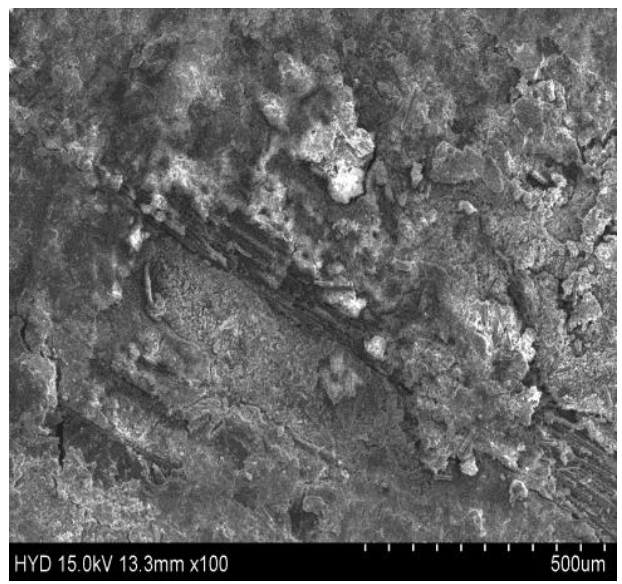

Fig.9(e). HNO3 Treated Composite Sheet 


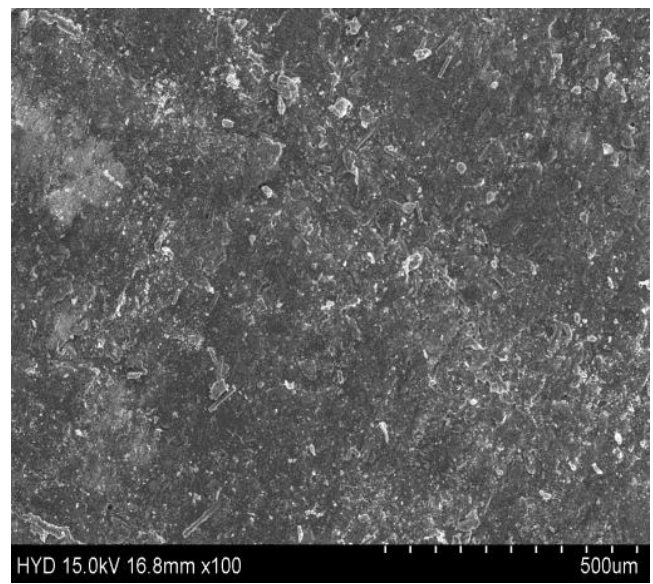

Fig.9(f). MWCNT-F Deposited on CF Composite Sheet

Scanning electron microscopy images are also taken on composite sheets fabricated for CF (wt 5\%) for all the samples with different surface treatments performed on CF. It is clearly observed from Fig9(d) that, the bonding strength is very weak for CF treated with surface oxidation treatment and inter laminar shear forces between all the ingredients is very less. From Fig 9(e), it was observed that, $\mathrm{HNO}_{3}$ treated $\mathrm{CF}$ composite specimen exhibits partial bonding strength and cohesive attractive forces between all the ingredients is better compared to Fig 9(d). The composite specimen containing CF grafted with MWCNT-F from fig 9(f) exhibits high bonding strength and good inters laminar cohesive forces between the ingredients compared to remaining treatment methods. There may be chance of increase of strength of the composite after $\mathrm{CF}$ grafted with MWCNT-F compared to $\mathrm{HNO}_{3}$ treatment method. MWCNT-F grafted on CF composite sheet is shown in fig 9(f). The grains are distributed uniformly throughout the surface all the ingredients possess good bonding with resin.

\section{Tensile and Flexural Test Results}

The basic important tests to evaluate the properties of a friction material are tensile and flexural tests. The strength of any friction material is determined by conducting a tensile test and the amount of maximum load carried by the specimen is determined by conducting flexural test using three point bending method. The Instron testing machine of model No 8801, shown in fig 10 (a) is used to evaluate the ultimate tensile strength and flexural strengths of the materials. The machine is equipped with separate tensile and flexural test fixtures for mounting the specimens and the load is applied gradually until the specimen fractures. The values of ultimate tensile strength and flexural strengths of all the specimens with variation of surface treatments are tabulated. The best configuration of ingredients and surface treatment methods having good tensile and flexural properties are considered for design and fabrication of friction material in automobile applications.

\subsection{Tensile Test}

Tensile test is the basic important test to evaluate the strength of any material. This test is performed on all fabricated samples with varying surface treatment methods on CF. The machine is equipped with advanced load cell technology for faster testing and reduction of inertia errors. Tensile test is performed based on ASTMD638-02a standard of (Type1) shown in fig 10(f). The specimens before test and after test are indicated in fig 10(b), fig 10(c), fig 10(d) \& fig 10(e). 


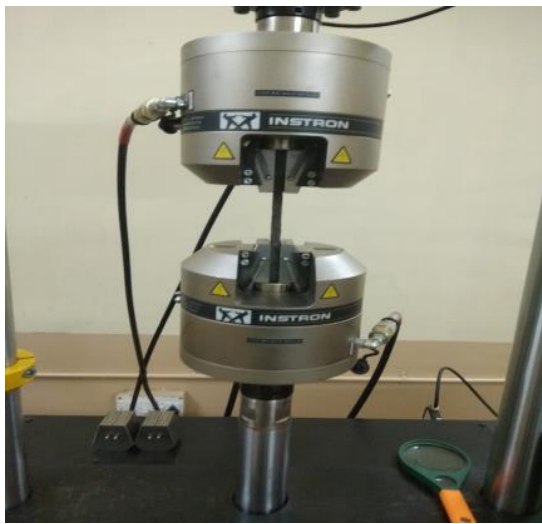

Fig.10(a). Tensile Test Apparatus

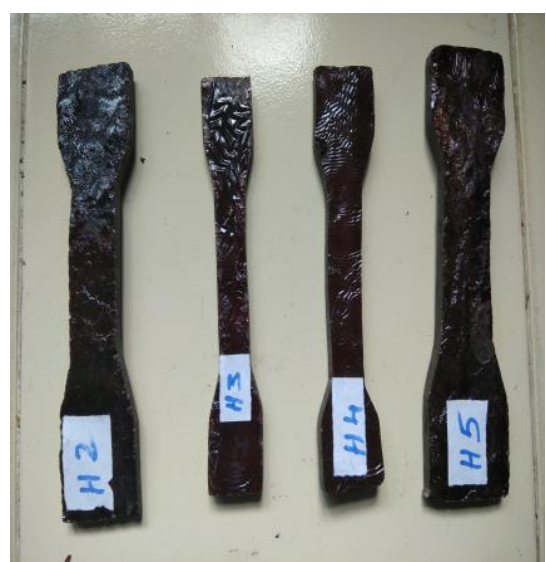

Fig.10(c). HNO3 Treated CF Before Tensile Test

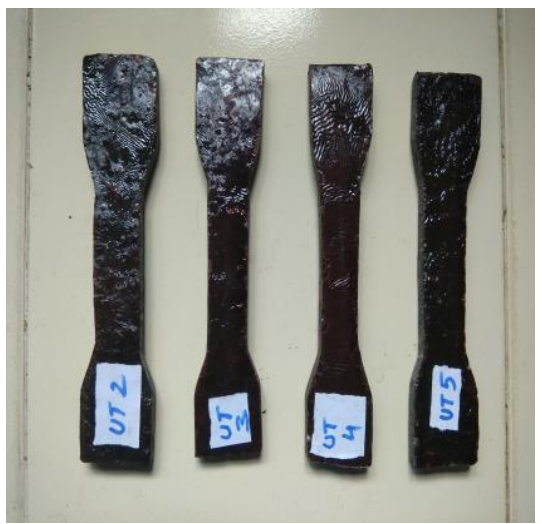

Fig.10(b). Oxidation Treated CF tensile test Specimens

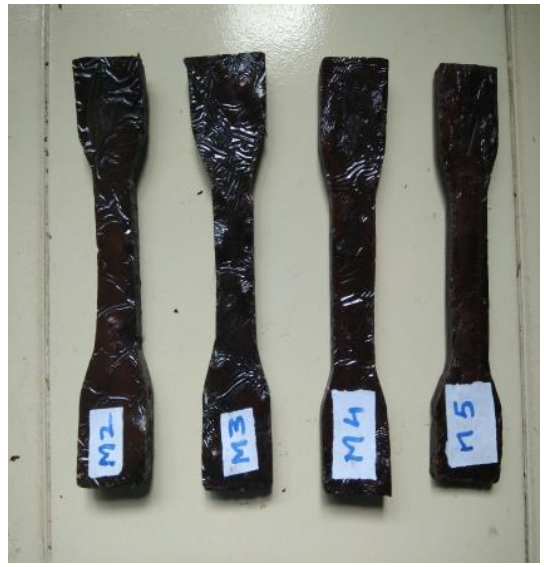

Fig.10(d). MWCNT-F Grafted on CF Before Tensile Test

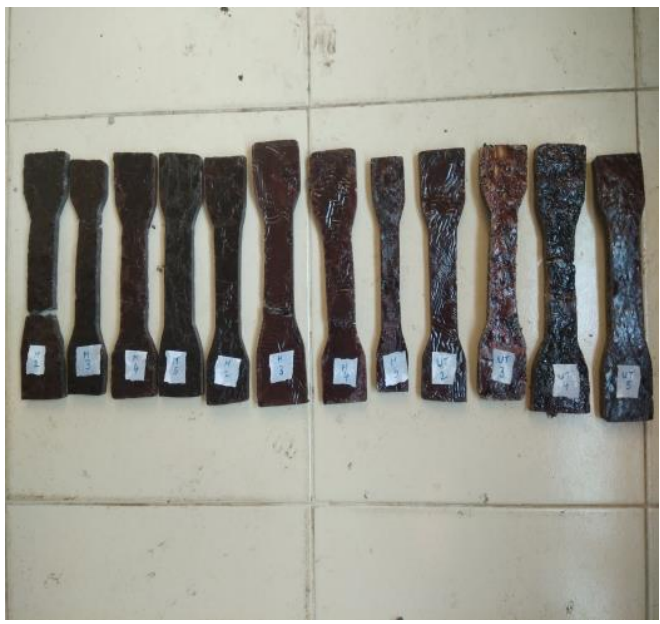

Fig.10(e). Specimens after Tensile Testing 


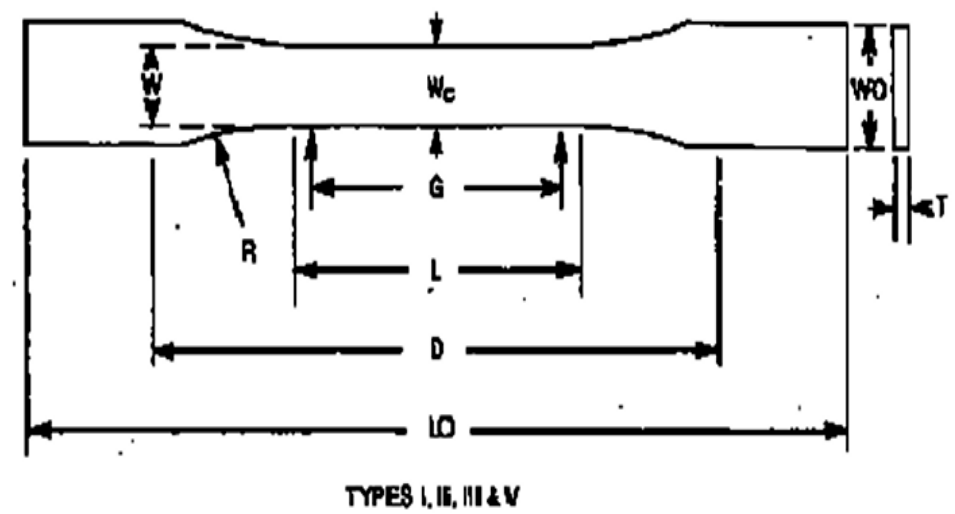

Fig.10(f). Tensile Test Specimen as Per ASTM Standard

The notations used in Fig 10 (f) are indicated with the dimensions Lo - Overall length 165(6.5) mm, DDistance between grips 115(4.5) mm, L- Length of narrow section 57 (2.25) mm, G- Gauge length 50(2) mm, R- Radius of fillet 76(3.0) mm, Wo- Width overall $19(0.75) \mathrm{mm}$, Wc- Width of narrow section $13(0.50) \mathrm{mm}$, $\mathrm{T}$ - Thickness of the specimen $10(0.50) \mathrm{mm}$.

Initially, the specimens are fixed between two clamping jaws firmly and loaded gradually with incremental load until failure of the specimen takes place. The values of deformation against each load are noted and tabulated. The breaking load for each specimen is noted and ultimate tensile strength values of all the samples with varying surface treatments are observed and indicated in table 4.

Table 4. Ultimate Tensile Strength Values of Specimens

\begin{tabular}{cccc}
\hline Type of composite & $\begin{array}{c}\text { Maximum load } \\
(\mathrm{KN})\end{array}$ & $\begin{array}{c}\text { Load at break } \\
(\mathrm{KN})\end{array}$ & $\begin{array}{c}\text { Ultimate tensile } \\
\text { strength(Mpa) }\end{array}$ \\
\hline UT2 & 1.421 & 0.93 & 7.11 \\
UT3 & 0.914 & 0.56 & 4.57 \\
UT4 & 1.296 & 0.79 & 6.48 \\
UT5 & 1.038 & 0.98 & 5.19 \\
H2 & 1.534 & 0.94 & 7.67 \\
H3 & 2.487 & 1.54 & 12.44 \\
H4 & 0.792 & 0.48 & 3.96 \\
H5 & 2.958 & 2.28 & 14.79 \\
M2 & 8.968 & 8.01 & 44.84 \\
M3 & 9.129 & 7.06 & 45.65 \\
M4 & 10.304 & 10.17 & 51.52 \\
M5 & 14.571 & 14.09 & 72.86 \\
& & & \\
\hline
\end{tabular}


From table 4, it was observed that, the sample S5 with (MWCNT-F grafted on CF wt5\%) with remaining ingredients can sustain more load (i.e $14.09 \mathrm{KN}$ ) and possess high ultimate tensile strength value (i.e $72.86 \mathrm{MPa}$ ) compared to remaining formulations of the material. This sample specimen S5 (MWCNT-F grafted on CF wt5\%) with selected ingredients possess increase in bonding strength between all the ingredients to enhance its mechanical strength. The main reason to have better tensile properties for the sample specimen S5 is having (CF wt5\%) and grafting MWCNT-F on CF surface to reduce chemical inertness of the CF surface and increase carboxyl groups on its surface for better absorptive characteristics with resin. The load carried by the specimen is taken initially by the fiber and transmitted to the ingredients. Therefore, CF selected for the given application by grafting MWCNT-F on its surface have the greater ability to sustain the applied load after mixing with all the ingredients and polymer matrix.

\subsection{Flexural Test}

Flexural test is performed on all specimens by mounting a three point bending load fixture, shown in fig 11 (a). The sample to be tested is placed on the two end supports and a concentrated load is applied at the centre of the specimen. This test determines the maximum amount of load carried by the specimen under bending load. The samples to be tested are shown in fig 11(b) and fig 11(c) and fig 11(d).

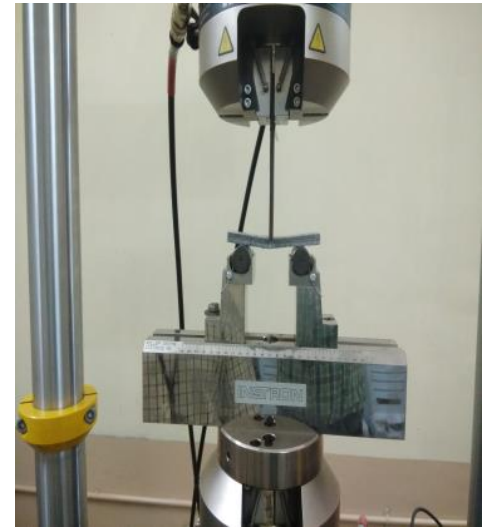

Fig.11(a). Flexural Test Apparatus

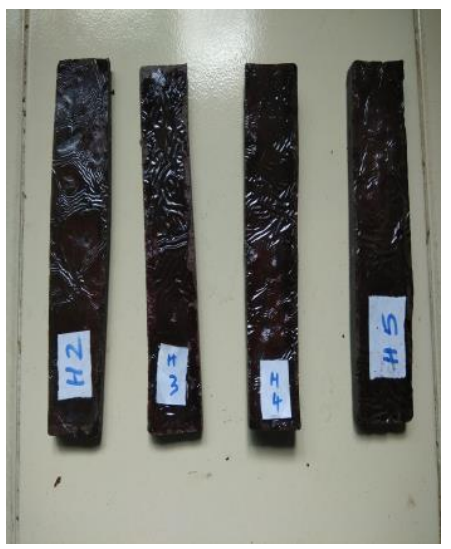

Fig.11(c). HNO3 Treated CF Flexural Test Specimens

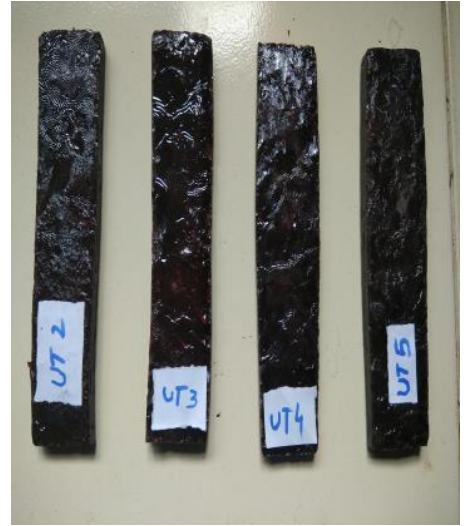

Fig.11(b). Oxidation Treated CF Flexural Test Specimens

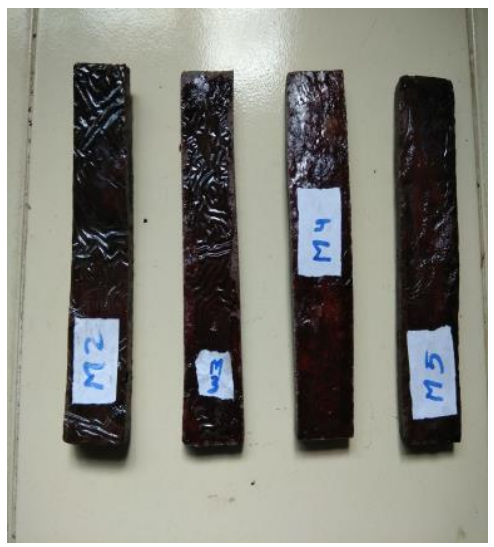

Fig.11(d). MWCNT-F Grafted on CF Specimens 
This flexural test is useful for predicting the behavior of friction material against the bending load carried by the specimen. This data enables to calculate the maximum permissible bending load carried by the material under static conditions of automobile, which is useful for friction material design at the starting stage. The values of maximum flexural bending load and corresponding flexural stress for variation of surface treatments performed on $\mathrm{CF}$ is given in table 5 .

Table 5. Flexural Stress Values for all Samples

\begin{tabular}{|c|c|c|}
\hline $\begin{array}{l}\text { Type of } \\
\text { composite }\end{array}$ & $\begin{array}{l}\text { Maximum } \\
\text { flexural load } \\
(\mathrm{KN})\end{array}$ & $\begin{array}{c}\text { Flexural stress } \\
(\mathrm{Mpa})\end{array}$ \\
\hline UT2 & 0.097 & 5.49 \\
\hline UT3 & 0.731 & 41.14 \\
\hline UT4 & 0.22 & 12.42 \\
\hline UT5 & 0.613 & 34.51 \\
\hline $\mathrm{H} 2$ & 0.09 & 5.49 \\
\hline H3 & 0.18 & 10.57 \\
\hline $\mathrm{H} 4$ & 0.097 & 5.49 \\
\hline H5 & 0.191 & 10.79 \\
\hline M2 & 1.261 & 70.965 \\
\hline M3 & 0.942 & 53.022 \\
\hline M4 & 2.247 & 126.43 \\
\hline M5 & 3.095 & 174.11 \\
\hline
\end{tabular}

From table 5, it was observed that, sample S5 with (MWCNT-F grafted on CF wt5\%) along with remaining ingredients can sustain more bending load (i.e 3.095KN) and possess high flexural strength value (i.e 174.11 $\mathrm{MPa}$ ) compared to remaining formulations of the material. This sample specimen S5 with selected ingredients can sustain more bending load and can extend its application in fabrication of brake friction material. The main reason to have better flexural properties for the sample specimen S5 is having (CF wt5\%) along with other ingredients. The load carried by the specimen is initially transmitted to the fiber and then it is transmitted to the ingredients. The surface treatments performed on sample specimen S5 is also the main reason to have high bonding strength between all ingredients. The ingredients and surface treatments performed on fiber can increase the inter laminar cohesive forces with resin and can sustain more bending load. The fiber surface after grafting MWCNT-F on CF possesses good bending strength. The fiber surface is not damaged and fiber/matrix adhesion is greatly improved without any de lamination and transverse cracks on the surface. Therefore, grafting MWCNT-F on CF (S5) can sustain more bending load compared to other methods. 


\section{Conclusion}

Tensile and flexural properties of the friction material specimens are determined by variation of surface treatment performed on $\mathrm{CF}$ (Oxidation, $\mathrm{HNO}_{3}$, and MWCNT-F). The weight loss and bonding strength of all the samples are determined by using thermo gravimetric and FTIR analysis. Based on thermo gravimetric and FTIR analysis performed on all specimen sample powders, it was observed that sample S5 (MWCNT-F grafted on $\mathrm{CF}$ wt5\%) with remaining ingredients possess low weight loss and good bonding strength with increase in temperature and wavelength compared to other formulations. It was observed that, tensile and flexural properties of the samples S5 (MWCNT-F grafted on CF wt5\%) with remaining ingredients is greatly improved. The specimen S5 possesses high ultimate tensile strength $(72.82 \mathrm{MPa})$ and flexural strength $(174.11 \mathrm{MPa})$ compared to remaining surface treatment methods and other formulations of the material. It was concluded that, optimum selection of ingredients for the sample specimen S5 and surface treatment method of grafting MWCNT-F on CF surface is responsible for improvement of tensile and flexural properties of friction material.

\section{Acknowledgement}

The authors would like to thank Anits Engineering College, Visakhapatnam for providing the chemical laboratory facilities for doing this project. The authors also thank Gitam University, Visakhapatnam for giving permission to carry out tensile and flexural tests using Instron testing machine.

\section{References}

[1] Liu Y, Kumar S. Recent progress in fabrication, structure, and properties of carbon fibers. Polym Rev2012; 52(3-4):234-258.

[2] Paiva JMF, Santos AN, Rezende MC. Mechanical and morphological characterizations of carbon fiber fabric reinforced epoxy composites used in aeronautical field. Mater Res 2009; 12(3); 367-374.

[3] F.Rezaei, R.Yunus, N.A.Ibrahim, Effect of fiber length on thermo -mechanical properties of short carbon fiber reinforced polypropylene composites.Mater.Des.30 (2009)260-263.

[4] T.W. Chou, L.M .Gao et al, An assessment of the science and technology of carbon nano tube -based fibers and composites, compos. Sci. Technol. 70(2010)1-19.

[5] Tanaka K. Friction and wear of glass and carbon fiber filled thermoplastic polymers. Journal of Lubrication Technology, 1977, 99: 408-414.

[6] Niels De Greef, Luman Zhang et al. Direct growth of carbon nano tubes on carbon fibers ; Effect of the CVD parameters on the degradation of mechanical properties of carbon fibers, Elsevier, Diamond \& Related materials 51(2015)39-48.

[7] Mohit Sharma, shanglin Gao, Edith Mader et al. Carbon fiber surfaces and composite interface .Elsevier, composites science and technology 102, 2014,35-50.

[8] Qiang Song, Ke-zhi Li et al. Grafting straight carbon nano tubes radially on to carbon fibers and their effect on the mechanical properties of Carbon/Carbon composites, Elsevier, Carbon, Volume 50, Issue 10, 2012, 3949-3952.

[9] S.P.Sharma, S.C.Lakkad. Effect of carbon fibers on the tensile strength of CNTs grown carbon fiber reinforced polymer matrix composites. Elsevier, Composites Part A 42(2011), 8-15.

[10] Hui Qian, Alexander Bismarck et al. Carbon nano tubes grafted carbon fibers: A study of wetting and fibre fragmentation. Elsevier, composites: Part A 41, 2010, 1107-1114.

[11] Febo Severini, Leonardo Formaro and Mario Pegoraro, et al. Chemical modification of carbon fiber surfaces. Carbon, vol.40, 2002, 735-741. 
[12] Long-gui Tang, John L.Kardos. A Review of methods for improving the interfacial adhesion between carbon fiber and polymer matrix. Polymer composites, vol18, 1997, 100-113.

[13] K.Naresh Kumar, K.N.S. Suman. Effect of pad and disc materials on the behaviour of disc brake against fluctuating loading conditions. Journal of automobile engineering and applications .2017; 4(2), 22-34.

[14] Naresh Kumar Konada, K.N.S. Suman. Effect of pad and disc materials on the behaviour of disc brake against dynamic high speed loading conditions. International journal of automotive engineering and technologies, Academic paper, Vol 6, Issue3 (2017), 116-128.

[15] C Venkateshwar reddy et al. Effect of various filler materials on inter laminar shear strength of glass epoxy composites, MECS press, International journal of engineering and manufacturing, 2016, vol5 , 22-29.

[16] D Sameer Kumar, K.N.S.Suman. Selection of magnesium alloys by MADM methods for automobile wheels, MECS press, International journal of engineering and manufacturing, 2014, vol2, 31-41.

[17] D Chan and G W Stachowiak. Review of automotive brake friction materials. Proc. Instn Mech. Engrs, Vol218 2004, part D: J.Automobile Engineering 953-966.

\section{Authors' Profiles}

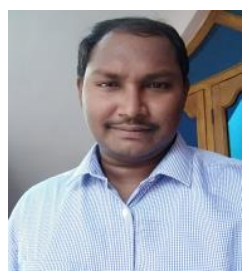

Naresh Kumar Konada was born in 1986, India. He has completed his post graduation in the field of Machine Design from GITAM University during the year 2010. He has been working as an Assistant Professor in the department of Mechanical Engineering, Anits Engineering College, and Visakhapatnam since 2010. His areas of interests include Composites, Nano Technology, Vibrations, and Vehicle Design.

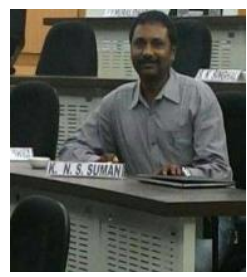

K.N.S. Suman has received Ph.D. degree from Andhra University, Visakhapatnam in 2006. His thesis was selected as best thesis during that year by Andhra University. He was the recipient of Senior Research Fellowships from UGC and CSIR. His area of research interest includes the preparation of Natural Composite Materials, analysis and their applications in Mechanical Engineering.

How to cite this paper: Naresh Kumar Konada, K.N.S.Suman,"Effect of Surface Treatments on Tensile and Flexural Properties of Carbon Fiber Reinforced Friction Material", International Journal of Engineering and Manufacturing(IJEM), Vol.8, No.3, pp.23-39, 2018.DOI: 10.5815/ijem.2018.03.03 